\title{
En memòria de Juli Busquets
}

Faustino M iguélez; G abriel Cardona; Carlota Solé; Toni Tulla; Joan Botella; M aria Pia Barenys

U niversitat Autònoma de Barcelona. D epartament de Sociologia

08193 Bellaterra (Barcelona). Spain

\section{Faustino Miguélez}

Juli Busquets siguió teniendo, hasta el final, las tres personalidades vinculadas a las tres profesiones que había ejercido durante la mayor parte de su vida: militar, político y académico. Los que nos dedicamos a esta rara profesión que es la sociología nos definimos, cuando nos obligan a ello, de muy diversas maneras: sociólogos, investigadores, profesores. Cuando él se llamaba «sociólogo» se creía un soldado de la sociología, con el objetivo primordial de cumplir con su deber, de estar siempre ahí, a disposición de lo que indicase el D epartamento o la Universidad.

Cuando yo lleguéa la U AB, en 1973, Juli Busquets no estaba en el núcleo central en el que se encontraba el $D$ epartamento y la mayoría de los profesores de Sociología, en Económicas. Estaba en Letras, más concretamente en G eografía... M uy pocas veces aparecía por el D epartamento, en realidad tenía su autonomía en lo que al gunos llamaban entonces las «colonias», los territorios exteriores al núcleo central en los que se enseñaba esa asignatura... Años más tarde entendí por qué una persona que había estado entre los fundadores de la sociología en la U AB se había retirado de ese núcleo y se había confinado en su reducto. Como en todas las pequeñas y grandes estructuras sociales que comienzan, se estaban gestando las líneas del poder, mediadas por la presencia de sociólogos de «renombre» que acababan de venir de fuera. Y como para él la universidad no era una arena de lucha por el poder, sino una institución que no debía ser contaminada, prefirió quedar apartado, dedicándose a la ense ñanza como un simple soldado de a pie. Las luchas políticas estaban, para él, fuera de la universidad, como demostró sobradamente.

Y allí estuvo durante muchos años, aún cuando ya era más «famoso» porque había entrado directamente en la política. Por el contrario, durante casi toda su etapa de diputado mantuvo una parte de su docencia, a pesar de que ni se le exigía ni se le pagaba por ello. C reía que no podía dejar de ser universitario.

EI D epartamento de Sociología de la U AB sufrió una cambio radical tras la muerte de J.F. M arsal y la marcha de A. de M iguel. N inguno de los que quedaron era funcionario, ninguno era catedrático; éramos casi todos un colectivo de «pares». Entonces volvió Juli Busquets, pero no para demandar ningún privilegio basado en la veteranía, sino para ponerse a disposición, tanto 
más cuanto que empezábamos a darle vueltas a la idea de una facultad de políticas y sociología. Y entonces llegó al go que suele ser dramático - hasta cruento a veces- en la vida de un departamento en la universidad: las cátedras. Varios de nosotros tuvimos que convencer a Juli Busquets de que se presentase a la primera cátedra, y él lo aceptó con el talante de servicio de un soldado.

La cátedra de Juli Busquets, que él nunca ejerció como tal - en el sentido más universitario y peyorativo de ejercer de catedrático- y que impidió que ninguno de los otros que vinieron a continuación lo hiciera, es una de las razones que han hecho peculiar al D epartamento de Sociología, con una peculiaridad a la que se deben muchos de sus éxitos. Es decir, que éste sea un departamento en el que las propuestas y las políticas se discuten y las decisiones se toman entre todos, los cargos no están predeterminados, el trabajo se reparte igualitariamente, los recursos se reparten igualitariamente.

Juli Busquets siguió siendo un soldado de la sociología, a pesar de que, para la mirada formalista de muchos, llevaba los galones de comandante del cuerpo, si puedo seguir con el símil. N unca se impuso para reivindicar un cargo, exigir una asignatura o pedir menos trabajo, ni para demandar un privilegio de ningún tipo. Era una persona realista que jamás quiso aprovecharse de ningura apariencia para convertir las categorías en privilegios.

Pero Juli Busquets era un convencido de la política. H izo política desde el Ejército, cuando creyó que eso era necesario para contribuir a cambiar las cosas, y por esa razón hubo de sufrir sanciones. H izo política en la nueva escena democrática española como diputado en el Parlamento de España, aunque nunca hizo política en la universidad. Pensaba que la actividad universitaria tenía que estar por encima de las diferencias y de los partidismos.

Pero haciendo política, siguió siendo sociólogo. Fue un fino analista de los de su primera profesión, los militares, de sus vicios y virtudes. Lo demostró en numerosos escritos sobre los militares, sobre la guerra, sobre los ejércitos. También en incontables debates y conferencias. Su libro El militar de carrera en España es seguramente el mejor análisis que sobre ese tema se ha hecho en nuestro país. Pero seguía siendo estudioso de la tercera de sus profesiones, la política. D edicaba buena parte de su tiempo libre en el C ongreso a rebuscar en la biblioteca y en los archivos del mismo. Intentaba entender, desde la sociología, la idiosincrasia de sus compañeros de profesión, los políticos, y no dudaba en criticarlos cuando lo creía adecuado.

Juli Busquets era un convencido de que todo se logra con el trabajo. Y así fue hasta el final. Poco antes de la última N avidad nos llamó a dos de nosotros y nos contó su situación. Era perfectamente consciente de lo que pasaría y del tiempo que le quedaba. No atendió, ni entonces ni más tarde, a las peticiones que le hicimos de tomar la baja o de reducir su dedicación. Q uería trabajar hasta el final, deseaba acabar proyectos que tenía en marcha. Sin saberlo, optaba por la mejor forma de combatir la enfermedad. Siguió dando clases y cumpliendo todas sus obligaciones. Aceptó la muerte con la serenidad de un trabajador que sabe que siempre ha cumplido con su deber. H asta el punto de 
asumir la carga docente habitual para el curso 2001-2002, a pesar de que su salud se deterioraba.

De Juli debemos recordar sobre todo la autoexigencia en el cumplimiento de sus obligaciones - que jamás tradujo en críticas hacia quienes pudiesen cumplir menos las propias- y la predisposición total para ayudar a quienquiera que le pidiese ayuda. Con su muerte hemos perdido a un gran compañero. 


\section{Gabriel Cardona}

No puc ni vull fer una disquisició acadèmica sobre el tema, perquè la meva relació amb el Juli sí que va ser acadèmica, però va ser sobretot sentimental. D oblement company a l'Exèrcit i a la U niversitat i un dels millors amics que mai he tingut, va construir-me part d'allò que abans s'anomenava «l'anima».

Ens vam conèixer durant el procés de Burgos de 1970; jo en aquell moment no coneixia cap militar demòcrata. Ú nicament havia tingut relació amb un capità mallorquí, Joan M artí Rosal, que avui és mort, i que era una persona de comportaments molt civilitzats, i penso que era un home demòcrata, malgrat que no gosava fer manifestacions polítiques. Era un militar que professava valors democràtics en un exèrcit terrible, procedent de la guerra civil, un exèrcit que ni feixista podia ser de tan antiquat i reaccionari; malgrat tot, ser feixista requeria una càrrega de modernitat que els militars d'aquella època eren incapaços d'assumir. En aquell ambient, trobar un militar aficionat a llegir i que, a més, tingues sensibilitat per les qüestions morals que vertebren la democràcia, semblava impossible.

El cas va ser que, durant el procés de Burgos, un tinent mallorquí amic meu, $M$ artí Rotger, que estudiava econòmiques i que, jugant-se un disgust, presumia de ser marxista en aquells temps, va presentar-me Juli Busquets, de qui jo havia llegit El militar de carrera en España. Per mi, conèxxer el, en aquell temps, capità Busquets era molt més important que conèixer qual sevol altra persona, perquè el seu llibre m'interessava molt i perquè em semblava fonamental contactar amb un militar demòcrata.

Realment, el M artí va presentar-me el Juli amb la perversa intenció que jo signés un manifest que el Juli havia preparat. Un fill del coronel O rdovás, un genet molt prestigiós que presidia el tribunal de Burgos, havia estat agredit per desconeguts $\mathrm{i}$, com a resposta, uns dos-cents cinquanta militars de cavalleria destinats a $M$ adrid, havien signat un manifest demanant més duresa al govern.

En aquella època érem jovesi bastant innocents; per nosaltres, tots el franquistes eren iguals, la qual cosa no era certa. A l'interior del franquisme calia fer matisacions, i el govern d'aquells moments, format per C arrero Blanco y ministres membres o propers a l'O pus D ei, estava inspirat per López Rodó i era més civilitzat que els sectors falangistes i militars. Efectivament, el govern Arias, format a la mort de C arrero, va ser molt mes dur, fins a l'extrem d'executar set condemnats, mentre que el govern C arrero no va matar ningú.

Dintre del franquismehi havia tendències, diferències i una aferrissada lluita entre elles. En aquells moments, els ultres pretenien pressionar amb el manifest dels dos-cents cinquanta militars de M adrid i conduir el govern cap als seus territoris. «Para volver a levantar las banderas del 18 de julio», com deia Blas Piñar, un personatge del Pleistocè, que surava en aquells moments. Busquets pretenia evitar que, amb l'assumpte de Burgos, es matés al guna persona i que els ultres fessin caure el govern, que era menys intransigent que ells mateixos.

Els personatges de Fuerza N ueva, el partit que dirigia B las Piñar, atacaven Carrero i l'insultaven anomenant-lo «el C ejas», la qual cosa no seria més tard 
inconvenient perquè, a la mort de Carrero a mans d'ETA, el consideressin un màrtir de la pàtria i publiquessin les seves obres completes.

Dintre d'aquesta baralla interna per decidir si, en el futur, el règim seria tan dur com era o encara més, els reunits per Juli Busquets vàrem entendre que calia oposar-se a la maniobra dels ultres. El Juli ens va dir que calia compensar el correu negre de dos-cents cinquanta militars de M adrid, amb un contramanifest moderat de suport a la disciplina castrense, en contra de les pressions dels nostres companys de $\mathrm{M}$ adrid.

Com que els ultres reclamaven penes de mort, més duresa i l'estat d'excepció, vam decidir buscar, entre els nostres companys, quins serien capaços de signar un document moderat. Sols van aconseguir onze signatures, comptant les nostres mateixes. D els signants, nou eren capitans i dos, una mica més joves, tinents, $M$ artí Rotger i jo mateix.

El nostre manifest afirmava que estàvem contra la indisciplina dels companys de $M$ adrid i que no acceptàvem les seves pressions sobre el govern. Per oficials en actiu, subscriure col'lectivament un document d'aquelles característiques era un delicte de sedició, previst i penat al Codi de Justícia M ilitar. A través de diverses persones, van rebre còpies del document el príncep Joan Carles, el general Díez Alegría i Carrero Blanco. El govern, col·locat en el dilema de processar onze militars per dir una cosa i dos-cents cinquanta per dir la contrària, va arxivar els dos manifestos, però la maniobra ultra va quedar desactivada. El procés de Burgos no va costar la vida de ningú ni va desplaçar el govern per un altre d'ultres d'el grupet de militars aglutinats pel Juli, entre els homes del franquisme dur i el franquisme assassí, havia ajudat els primers, malgrat que el que volien era la democràcia.

Aquella primera acció ens va fer decidir. Estàvem convençuts que es produiria un cop militar, perquè ens arribaven notícies contínuament i sols calia activar algun dels plans que estaven preparats a l'Estat $M$ ajor per cas d'emergència i que permetien ocupar militarment els punts fonamentals de tot Espanya. Semblava probable que, a la mort de Franco o una mica abans, sintentés crear una junta militar o un govern ultradretà. Com que era l'època de la dictadura argentina i de la seva guerra bruta, temíem que aquí pogués produir-se alguna cosa semblant i coneixíem militars que propugnaven aquella situació. M algrat tot, el conjunt de l'Exèrcit no era políticament tan actiu com sembla, era clarament franquista però també disciplinat, perquè la llarga dictadura de Franco I'havia fet obeir sense protestar en qualsevol circumstancia. Era com una d'aquelles grans feres que, sobre un tabalet de circ, obren la boca, sembla que amenacen però no baixen del setial fins que vol el domador. L'Exèrcit sols era un gran felí a les ordres de Franco, però ningú no ho sabia en aquelles dates, ni nosal tres tampoc. Sols coneixíem la mentalitat franquista dels nostres companys i la decisió d'un petit, però molt actiu, grup de militars ultres connectats amb l'extrema dreta i que les seves mirades apuntaven, en aquells moments, cap a l'Argentina. L'Exèrcit es dividia en tres grups: els ultres, que eren minoritaris però escridassaven molt; la gran massa franquista però inactiva políticament i disposada a fer el que li manessin, i, per 
últim, el petit grup de militars demòcrates, en bona part aglutinats al voltant de Busquets o les seves influències.

Juli era el principal dinamitzador del corrent democràtic militar. Combinant les il/lusions amb les males notícies i la por, en l'ambient barceloní farcit de conspiradors, els militars demòcrates vàrem començar a conspirar juntament amb un altre grup de funcionaris que tampoc no tenia facilitats per organitzar-se contra la dictadura: els jutges i els magistrats. D' 'aquelles reunions absolutament secretes, en sortirien, més endavant, Justícia D emocràtica, per un cantó, i la U nió M ilitar D emocràtica, per l'altre.

La situació ens costava molt, perquè l'Exèrcit és una institució que té pre vistes totes les crisis i està acostumat a controlar-les. Per ai xò ens costava molt conspirar, perquè, quan aplegàvem tres companys, un podia ser dels serveis d'informació 0, anar-se'n de la llengua per por o per disciplina. Aquestes dificultats varen multiplicar-se en fundar la U M D ; el mateix capità de la Policia Armada que havia fet el nostre pla de seguretat, ens va trair i, més tard, va actuar com a testimoni del fiscal militar. Per les ironies de la vida, aquella mateixa persona seria després un dels mes alts càrrecs del ministeri de Barrionuevo.

Era molt difícil fer proselitisme a l'interior del cos d'oficials. M estrestant, la vida continuava i nosaltres treballàvem, estudiàvem, fèiem tesis, escrivíem amb pseudònim i, un dia, el Juli, que era el que pensava les coses, va decidir organitzar una assignatura nova d'historia de la guerra en aquesta mateixa universitat. Fer una història de la guerra en un estat dominat per la dictadura era entrar en una normalitat acadèmica aquí desconeguda. Avui tenim un llibre titulat Enciclopedia del Arte de la Guerra, escrit per un tinent general espanyol, la qual cosa expressa el paral·lelisme amb qualsevol universitat estrangera però, en aquell temps era una mena d'heretgia. En canvi, avui, vivim en un estat on un tinent general és capaç de publicar més de sis-centes pàgines sobre aspectes del seu ofici sense dir disbarats. És un canvi considerable des d'aquelles fosques èpoques, quan únicament parlaven d'aquestes qüestions a la U niversitat persones com Ricardo de la Cierva.

N osaltres preteníem tractar-les amb rigor i normalitat; per un cantó, fèiem la nostra tasca acadèmica i, per l'altre, fèiem créixer els sentiments i la complicitat democràtica entre els nostres companys militars. Penso, amb satisfacció, que algun d'aquells alumnes és avui professor universitari. M estrestant, a nosaltres, ens vigilaven els serveis d'informació militars i el SECED, a qui nosaltres anomenàvem la PID E, en comparació amb la policia política portuguesa. Ens queden moltes anècdotes per explicar, com aquella del dia que el màxim responsable del SECED a Barcelona, ens va proposar al Juli i a mi crear i dirigir a Poblet una alternativa a la U niversitat C atalana d'Estiu i ens va preguntar de qui podríem disposar com a col-laboradors. No crec que esperés altra cosa que intentar comprar-nos o aconseguir que li facilitéssim alguns noms dels intel·lectuals amb qui nosaltres teníem una relació més estreta. Sembla que ens van gravar tota la xerrada, però nosaltres ni vam acceptar l'encàrrec ni vam deixar anar informació. D e la Universitat Catalana d'Estiu ni de les JO N S ningú no va tornar a parlar-ne. 
Els militars reben, des que quasi són unes criatures, un ferm adoctrinament que els inculca un conjunt de valors entre els quals destaquen la disciplina i la fidelitat als seus comandaments. És de justícia dir que, en el meu cas, tenia molt clara la vocació democràtica, però em quedava el dubte de si, en organitzar una societat secreta militar, traïa la deguda fidelitat als meus comandaments. És possible que a alguna persona aliena a l'Exèrcit, això li sembli una ximpleria, però per un militar era molt important. Va ser Juli Busquets qui va donar-me la clau per resoldre els meus dubtes quan va dir-me: «La nostra fidelitat com a oficials es deu, en primer Iloc, al nostre poble».

Realment, ens va costar molts esforços portar endavant la U M D. Avui tothom es demòcrata de tota la vida, però en aquell temps no era així. Vam fer una llista de militars que, per al guna raó, pensàvem que podrien ser permeables a les idees de la democràcia i, com que a l'Exèrcit tothom es coneix, vàrem distribuir la feina entre nosaltres a fi que cadascun intentés captar els que coneixia, o eren de la mateixa promoció o tenien qualsevol altre lligam. La llista va ser exhaustiva i allí figuraven tots els oficials que, per la seva actitud, podien considerar-se permeables als nostres somnis de llibertat. D e tot allò va sortir un seguit de tres-cents o quatre-cents noms que van intentar, treballant en la precaució, de no ser descoberts, la qual cosa, naturalment, va resultar inútil, perquè ens van descobrir al cap de poc temps.

Aquesta feina va resultar difícil, dolorosa i perillosa des del primer dia. Estàvem contínuament sota sospita, sense permís per escriure, amb els telè fons intervinguts i vigilats per al guns dels nostres propis subordinats. Al quarter de Pedralbes, que era la meva destinació, hi van enviar més de trenta soldats, que eren inspectors de policia destinats a vigilar el s oficials sospitosos, i alguns sots-oficials van ser empleats pels serveis d'informació per vigilar els seus capitans. A més a més, va caure sobre nosaltres una sistemàtica persecució, molt disfressada perquè els alts comandaments militars volíen evitar l'escàndol que el públic conegués que existia un grup d'oficials acusats de ser demòcrates.

Prest vàrem entendre la necessitat de connectar amb les forces de l'oposició civil. La por era un sentiment tan corrent, que recordo el desconcert d'algunes persones que després van esdevenir molt importants a la política, quan els convidàvem a reunir-se una nit amb militars demòcrates. Va ser notable la cara de terror que va fer un d'aquells convidats quan, després de moltes voltes i giravoltes, va trobar-se amb cinc o sis de nosaltres, casa d'un capità de la Policia Armada i, a sobre, li vam dir, per tranquil-litzar-lo, que les entrades i sortides estaven protegides per policies vestits de civil. D 'aquelles entrevistes en recordo amb molta simpatia una amb Ruiz Jiménez, que ens va tractar com a companys, dient que ell mateix era tinent provisional del temps de la guerra i va insistir: «Sobre todo, no os sublevéis, no tengais una precipitación como la de G alán y García, sería una cosa terrible».

Els esforços van donar el seu fruit i la U M D va comptar amb uns dos-cents cinquanta militars, disposats no a donar un cop, sinó a evitar que el donessin elsultres, que tant ens inquietaven, perquè contínuament circulaven rumors que s'estava preparant un moviment o que algun general semblava disposat a aixe- 
car-se. Tot eren exageracions produïdes per aquella situació anormal, però ningú no sabia, en aquells temps, que el franquisme moriria amb Franco. $M$ entrestant, fèiem els possi bles per estar informats i per convèncer el s nostres companys, entre la bogeria d'un giravolt de rumors i maniobres de generals, falangistes i nostàlgics que no sabíem fins on podien arribar.

Juli Busquets tenia una vocació intel-lectual tan forta que fins i tot va redactar una bibliografia i un pla de formació per ser repartits clandestinament entre els oficials, amb la convicció quel'exercici intel·lectual faria canviar les postures dels militars.

Cal pensar que tots els alts comandaments eren, en aquells moments, veterans de la guerra civil molt allunyats dels principis que inspiren la democràcia. N 'hi havia alguns, com el general Gutiérrez M ellado, que van apostar seriosament pel canvi polític, perquè desitjaven evitar un nou enfrontament armat i una guerra civil. Per això ens resultava tan dificultós estendre el nostre pensament entre els militars.

Busquets no va ser processat com a membre de la U M D per la senzilla raó que ja estava empresonat. Cada any, per commemorar l'aniversari de la fundació de l'A cadèmia G eneral M ilitar, se celebrava a Barcelona un acte que solia rematar-se amb un discurs molt ultra, i aquell any entre el Juli, el López-Amor i jo vam preparar un discurs diferent. Com que no sospitaven el que passava, tots els oficials joves de la guarnició hi van donar el seu vistiplau. Va ser fàcil, perquè nosaltres estàvem preparats, sabíem el que volíem i els altres van ser agafats per sorpresa. Q uan els delegats dels diversos quarters, que majoritàriament eren de la U M D, van reunir-se a Capitania General, Busquets i Julve, a més de defensar el discurs preparat, van denunciar que un capità d'Enginyers havia estat represaliat per negar-se a donar els noms dels sindicalistes de REN FE. Com a resposta, Busquets $\mathrm{I}$ Julve van ser expedientats $\mathrm{i}$ empresonats a C euta $\mathrm{i}$ El Ferrol respectivament.

Per aquest motiu, a I'hora de reprimir la U M D, el pes va caure sobre la junta de M adrid i no sobre la de Barcelona, que era la capdavantera i la mes important. Aquesta situació fa ver aparèxer Luis O tero com a cap de la U M D, tot i que no era així. L'organització estava formada fonamentalment per capitansi sols per dos comandants: Busquets i O tero. D e manera que, pel fet de trobar-se Busquets empresonat a C euta, va ser detingut O tero, que era I'únic comandant a la vista. Però el fundador, el cap, el líder i el principal ideòleg de la U M D fa ser en tot moment Juli Busquets, que, quan va ser empresonat al castell d'El H acho, a C euta, va captar per a l'organització el mateix comandant militar de la presó. La U M D va néixer dels amics de Juli Busquets i, sense desitjar treure mèrits a ningú, els amics de Juli Busquets van vertebrar l'organització, escriure els seus documents i fer el primer proselitisme. M al grat això, únicament tres militars de C atalunya van ser detinguts, Gurriarán, LópezAmor y D iego, perquè el capità general de Barcelona patia una malaltia mortal i no va voler que fossin represaliats més oficials a les seves ordres.

$M$ al grat això, els detinguts van patir uns temors raonables, fins a l'extrem de témer que els traguessin del castell de Figueres per darles un paseo. En molts 
moments els que estàvem Iliures vàrem creure que patiríem un atemptat, cosa que no va passar, perquè el tigre del franquisme nostàlgic era de paper. Però, en aquells moments, ningú no ho sabia.

A més d'això, existeix una llarga i densa història acadèmica i política de Juli Busquets. Jo prefereixo parlar d'aquelles vivències íntimes, militars, universitàries i personals que vaig tenir amb el Juli; les més riques en il·lusions, entusiasme i por de la meva vida. Pels amics incondicionals de Juli Busquets que vàrem ajudar-lo a portar endavant la lluita per la democràcia; mai no hi haurà una il·lusió més gran, ni uns moments més intensos, ni una entrega mes entusiasta com la d'aquells temps, quan ens vàrem jugar tot el que teníem per la llibertat del nostre poble.

Però el que més s'hii va jugar va ser el Juli, el que més s'hi va entusiasmar va ser el Juli, el que més gent va empènyer va ser el Juli. Q uan parlo d'aquestes coses, em sento molt ferit per la seva desaparició i sento que, el dia que es va morir, a mi se'm va morir la meitat d'allò que, abans, sanomenava «'ànima». 


\section{Carlota Solé}

En la dimensió acadèmica, tant docent com investigadora, Juli Busquets fou un dels professors iniciadors de la docència en sociologia a la U AB l'any 1969, després d'haver-se format a d'altres universitats espanyoles. Compaginà les seves activitats polítiques amb les preocupacions per la docència universitària durant un temps molt prolongat. Va saber desvincular-se de la seva activitat política a la llum pública per continuar treballant en el si del seu partit polític, el PSC, fidel als seus ideals, i, parallelament, incrementà la seva dedicació a la universitat, que fou plena i profitosa, fins a la seva mort.

Es dedicà a la universitat durant més de trenta anys, però en l'últim període ensenyà, entre d'altres, una de les matèries que sempre el varen interessar intel lectualment i el colpejaren emocionalment. Em refereixo a l'assignatura d'Estructura Social, que amaga, en el seu si, el problema tan central de la desigualtat. Juli Busquets combatia la desigual tat entre les persones i els pobles, tant a les aules, informant i educant els alumnes, com en la recerca sobre països del Tercer M ón, 0 ajudant a acadèmics d'altres universitats de països endarrerits econòmicament i socialment. Un exemple, fou Cuba. La vinculació de Juli Busquets amb aquell país, que sinicià, si no abans, l'any 1976, en un viatge a I'illa - organitzat pel PSU C i un seguit de partits polítics que havien lluitat contra i sota el franquisme-, que es traduí més endavant en la participació com a docent a cursos a les universitats cubanes, en el constant suport a professors de la U niversitat de L'H avana i d'altres universitats d'aquell país perquè visitessin la nostra U niversitat Autònoma de Barcelona o publiquessin a la revista del D epartament: Papers. Revista de Sociologia.

Un altre aspecte que cal destacar de Juli Busquets és la seva participació en la lluita política contra el franquisme, contra el sistema econòmic i el règim polític vigent quan ell era jove, les dècades de 1950, 1960 i 1970. Profundament demòcrata en un temps $i$ en un lloc on era difícil ser-ho, és a dir, sota una dictadura i en el si de l'exèrcit, Juli Busquets vinculà l'activitat política (creant i actuant en la Unió de M ilitars D emòcrates des de 1974; presentant-se a les eleccions al Congrés dels Diputats l'any 1977, i un any més tard, contribuint a formar el Partit dels Socialistes de Catalunya) amb la reflexió teòrica sobre la societat quel'envoltava. N o solament, pels llibres $i$ els articles que va publicar sobre la sociologia de les nacionalitats, sobre la carrera militar i l'ensenyament militar, sobre els militars demòcrates, sobre els cops d'Estat a Espanya, sobre la dona en les forces armades espanyoles, ni per la seva docència sobre estructura social (recordo les moltes discussions que sovint encetàvem ell i jo sobre el contingut d'aquesta matèria, discussions que no confluïen en cap punt d'acord i només servien per demostrar-nos la tolerància i respecte que ens teníem, més enllà de moltes discrepàncies teòriques); sinó també, per la continuada incorporació d'elements de reflexió que la dimensió de sociòleg proporcionava a la seva activitat com a militant de base d'un partit polític, intentant promoure mesures i reformes per tal d'augmentar-ne la democràcia interna, fent evident la incompatibilitat de càrrecs de representació política, Iluitant 
per mantenir l'actuació del seu partit en la línia d'esquerres que ell considerava més eficient i honesta. Jo crec que fou precisament la seva dedicació a la sociologia, la seva predisposició a la reflexió constant sobre els problemes socials, a nivell macro i micro, el que li permeté deixar d'ocupar càrrecs públics, sense traumes, per dedicar-se de ple a l'estudi.

D 'aquesta vinculació entre activitat com a polític actiu i com a sociòleg docent i investigador se'n desprèn, al meu entendre, una última reflexió per als qui avui són joves i estudien sociologia, ciència política, economia o alguna altra ciència social (i no social). C rec que avui la participació i la lluita polítiques són, d'una banda, més fàcils que quan nosal tres érem joves, i, de l'altra, més difícils. Són més fàcils perquè hi ha més llibertat i més democràcia. Són més difícils per la indefinició i llunyania de l'enemic que cal combatre. N osaltres podíem personalitzar la nostra lluita en un general rebel a la República legalment constituïda (Franco) i en un règim polític opressor de les llibertats democràtiques, del fet nacional; responsable de la migradesa econòmica, cultural i intel-lectual, etc. Avui, tot vivint en la mateixa societat capitalista, els referents contra els quals cal Iluitar són comuns a la resta de societats articulades i funcionent en xarxa, en l'era de la globalització. Avui, es tracta de lluitar contra la inseguretat transnacional, contra l'amenaça de la guerra química o la bacteriològica i, en definitiva, contra la distribució atzarosa, imprevisible i sobretot universal dels mals i danys, conseqüència de la producció capitalista de béns i serveis. La distribució dels mals i danys com ara la contaminació i el deteriorament del medi ambient, la individualització extrema i la mercantilització de les relacions socials, com assenyalen Beck (1986) i Rifkin (2000), no afecta una única classe social o un col·lectiu específic, ni una regió o estat nació en concret, sinó tothom, tot el planeta. No hi ha cabuda tampoc per a solucions específiques, ni existeix cap assegurança calculable ni protecció possible, ni hi ha cobertura davant futurs mals i danys. Els atzars produïts per una societat traspassen els límits dels sistemes moderns convencionals de predicció i control. El futur no és un terreny preexistent cap al qual ens dirigim i per al qual ens preparem, sinó que nosaltres el creem, el construïm i li donem forma a través de les decisions que prenem individualment. Aquest reconeixement de la indeterminació intrínseca del futur i del nostre rol en donar forma a aquest futur, ens obliga a assumir la responsabilitat de la seva creació (Lash i altres, 1996: 10).

Les decisions que cal prendre davant dels perills nuclears o biotecnològics ja no són responsabilitat d'un grup d'experts, de científics, d'industrials emprenedors, del govern d'un estat-nació, o d'un dirigent polític. L'autoritat, en el sentit de $\mathrm{D}$ ahrendorf, per prendre decisions sobre els mals que, per atzar esdevenen desastres que afecten a tota la humanitat (independentment de pertànyer a una classe social alta o baixa, haver nascut en un país ric o pobre, ser de raça blanca o negra), no es troba en un únic col·lectiu o en un únic responsable, sinó que es distribueix i es fragmenta a través d'un nombre d'individus que formen grups socials (dispersos per tot el planeta) d'acord amb llurs interessos i en constant interacció. 
Avui, la participació i la lluita polítiques són més difícils que quan nosaltres érem joves, perquè no n'hi ha prou de seguir una idea o un sistema d'idees o una ideologia, i militar en un partit polític que persegueix un model de societat i, d'acord, amb això, dissenyar o imitar d'altres societats, les estratègies i polítiques per assolir-lo. Avui, és imprescindible tenir coneixement, si és possible, científic, sobre el que es vol combatre per transformar-lo. No és per casualitat que el coneixement hagi esdevingut, des de la dècada dels noranta, un factor de producció crucial, conjuntament amb el capital i el treball, en les societats de la informació, la societat de les noves tecnologies de la comunicació, que provoquen un increment espectacular de la productivitat multifactorial, especialment en el sector dels serveis. Però, a diferència del capital i el treball, el conéxement no es compra ni es ven, sinó que s'usa, s'utilitza. Ningú no queda desposseït totalment del coneixement adquirit, tot i que sigui arrendat per una empresa o una entitat aliena a l'individu (Rifkin, 2000).

H eus ací un factor de llibertat individual, però també de més responsabilitat individual davant la persistent desigualtat entre països, entre homes i dones, entre grups socials; davant la persistent explotació en el sentit marxista del concepte, ara per ara encara no superat, de la persistent exclusió d'uns envers els altres, segons criteris que van més enllà de la renda per càpita 0 els ingressos familiars.

Aquí, la sociologia, com d'altres ciències socials, adquireix un paper rellevant. Permet conèixer, des de perspectives teòriques diverses, com s'estructura la societat i com canvia. Ja no és un grup social, més o menys reduït, qui pren la iniciativa i l'impuls del procés de canvi social, de manera programàtica. És el conjunt o la majoria de la població de les societats (encara avui, malaura dament, només les específicament occidentals) la que pren consciència i esdevé capaç de decidir i actuar, racionalment i lliurement, sobre què cal fer, com, quan, amb qui, etc. Als inicis del segle Xxı i en la zona d'influència politicocultural occidental, una part de la població sustenta un nivell d'educació suficient per poder adquirir coneixements, processar informació i transmetre'n, per poder conectar-se amb d'altres individus o grups, conscienciar-se críticament i autoconfrontar ( com diu Beck) les transformacions socials, dissenyar estratè gies per aconseguir els objectius (polítics) que es proposin (C astells, 2000). Aquest coneixement pot induir i conduir a lluitar per a transformar la societat de formes i a través de canals diversos, però sobretot no necessàriament iguals als que eren els únics pensables en les dècades de 1950, 1960 i 1970, quan Busquets era jove.

Juli Busquets va aconseguir vincular l'activitat política amb la reflexió sociològica a través dels mecanismes i les institucions a l'abast en aquella època, per tal d'aconseguir l'entorn de llibertat, de diàleg i de tolerància que, juntament amb moltes altres persones sota el franquisme, permeten als joves d'avui reaccionar, sense constriccions externes, i lluitar contra les noves i velles formes d'injustícia d'arreu del món.

Un últim comentari personal sobre Juli Busquets. Crec fer-me ressò del sentiment del D epartament de Sociologia, al qual pertanyia, de la Facultat de 
Lletres, de la Facultat de Ciències de la Comunicació de la UAB; en afirmar que Juli Busquets mai no va defugir les seves obligacions ni els seus compromisos com a docent, com a investigador, com a membre del consell de redacció de la revista Papers, com a membre de l'Associació C atalana de Sociologia, com a president o membre d'alguna comissió del $D$ epartament o d'alguna altra institució acadèmica. Sempre tingué una actitud oberta i constructiva, relativitzant amb fina ironia i bon humor, tan importants en aquesta vida, algun petit ensurt de la vida quotidiana departamental. C rec que en tot moment es manifestà com un home coherent amb les seves idees, valent a l'hora de defensar-les, cordial i ple de bonhomia. U na bellíssima persona que ens ha deixat, però que nosaltres, els seus companys de feina i els seus al umnes, no deixarem de recordar.

\section{Bibliografia}

BECK, U. (1992). Risk Society. Londres: Polity Press, 1986.

CASTELLS, M . (2000). La era de la información, 2a edició. M adrid: Alianza.

LASH, S. i altres (eds.) (1996). Risk Environment and M odernity, Londres: Sage.

Rifkin, J. (2000). La era del acceso. Barcelona: Paidós. 


\section{Toni Tulla}

\section{Bon dia.}

Bé, primerament, m'agradaria excusar el professor Enric Lluch, que ahir va dir al vespre, que per motius de salut no li era possible venir, demanant que l'excuséssim i expressant el seu record i la seva solidaritat amb Juli Busquets, per tot el temps que havien passat plegats. Serà una mica difícil substituir-lo, però, ho intentaré explicant el paper que a mi em va correspondre viure juntament amb Juli Busquets. És a dir, que ho faré com a membre de l'antiga divisió de Ciències Socials de l'any 1969 en endavant; i al mateix temps, també, com a deixeble seu.

Jo vaig conèixer en Juli Busquets el curs 1963-1964, com a alumne d'una assignatura que era Teoria de l'Estat, la qual, per molts de nosaltres, fou molt engrescadora i positiva. Ens va explicar la nova constitució de lugoslàvia amb dos fets que llavors eren revolucionaris i molt exposats d'explicar - perquè ell encara era capità de l'Exèrcit- : I'autonomia dels estats, és a dir, la idea de la federació, i l'autogestió. També va presentar-nos revistes que en aquell moment eren molt noves com ara Cuadernos para el D iálogo, i ens va donar a conèixer autors com ara D uverger. Clar, avui, tot això sembla, diríem, menor, però en aquell moment jo crec que va ser molt important. Jo era el delegat de curs i, per tant, vaig mantenir una relació personal molt gran amb ell. Aquesta relació personal va fer que, uns quants anys més tard - el mes de març de l'any 1968, jo havia fet el servei militar, forçat per les obligacions d'aquella època, perquè no es donaven, ja, pròrrogues ni es podia anar a milícies- ens tornéssim a trobar quan jo feia guàrdies al G overn M ilitar. Llavors, ell va gestionar que jo fos el seu escrivent, i durant set setmanes vaig - bàsicament- ajudar-lo a transcriure els llibres que en aquells moments tenia entre mans. Abans, vaig haver de fer un petit exercici de gestió que va consistir a racionalitzar tot allò que tenia a veure amb la burocràcia, de manera que tingués temps per poder-ho fer. I això va anar molt bé. Però, llavors, va aparèxer un capità general - Pérez $\mathrm{N}$ ieto- que va fer una ràtzia total, i, tot i que els esforços de Busquets varen ser en va, cal reconèixer-ne la significació en un moment molt difícil. Per tant, jo diria que fou una persona molt compromesa. Això és fora de dubte. Vaig haver d'anar a la Companyia Especial Jaén 25 a fer maniobres, entre d'altres coses. En Juli va continuar treballant, i no solament per a mi, sinó per a d'altres persones represaliades en aquell moment. I va aconseguir, conjuntament amb un altre membre de la U nió M ilitar D emocràtica, un altre capità - actiu en aquell moment, que es creés una unitat d'allò que se'n deia PPE (Promoción Profesional en el Ejército), bàsicament orientada a la sociologia i a la psicologia. I en aquesta unitat, on hi havia persones molt diverses, com ara Jaume Lanaspa, Rafael Sunyol, Javier C respán, jo mateix, i altres persones, vàrem tenir una certa llibertat de moviments, que va permetre, precisament, que es poguessin plantejar tots aquells temes que es referien a la racionalitat en I'Exèrcit, que en aquell moment era una de les línies de treball de Busquets. Per tant, cal concloure que Busquets fou una persona molt compromesa amb el seu entorn. 
Potser fou d'ençà d'aquesta relació i de mantenir aquests contactes, primerament amb Jaume Lanaspa i després amb mi mateix, que vàrem col·laborar amb ell en diferents assignatures que ell impartia a ESAD E i en a una acadè mia que jo recordo que hi feia classes de sociologia de la Publicitat, que es deia A cademia N uevas Profesiones, de la V ia Laietana. D esprés, em va demanar si volia - aleshores jo treballava al Servei d'Estudis- venir a col·laborar amb ell aquí, a l'Autònoma, I'any 1970, a impartir unes pràctiques de, bàsicament, M etodologia i de Sociologia Rural. També, vull recordar que ell era una persona que treballava en equip. Ésa dir, mai no em va demanar de fer un encàrrec «i arreglat»», sinó que era algú que discutia els programes, que donava idees, i jo considero que va ser un bon mestre.

M és endavant, a través de Juli Busquets, vaig entrar a formar part de la D ivisió de Ciències Socials. Si fem una mica d'història, cal que ens adonem que en aquell moment hi havia tres persones: l'Antoni Jutglar - que era el catedràtic d'H istòria del Pensament Social - , l'Enric Lluch — que portava la Geografia - i en Juli Busquets - que portava la Sociologia- . Aquella era la tríada que dirigia la D ivisió. U na divisió que treballava els dissabtes - encara me'n recordo molt bé- , i a partir de la qual vaig anar introduint-me en els temes de sociologia i també de geografia. En aquest sentit, m'agradaria fer un recordatori. Es tracta del fet que jo havia assistit a les classes de Salvador $G$ iner, i també de D emografia amb Armand Sáez, al carrer Sant Antoni, a unes classes nocturnes que es feien d'una manera una mica il.legal - perquè eren persones que havien estudiat en aquella època a París-, que varen proporcionarnos uns coneixements, en aquest cas, de sociologia i de demografia. A mi em va agradar de fer aquelles classes, i recordo - i voldria recordar- els companys d'aquell moment. En el cas d'en Jaume Lanaspa, caldria afegir que va trobar altres feines - ja que era economista, com jo- en el món de la banca. J osé Luis C ano - després d'uns fets una mica especials i que ell no va poder evitar - va haver de passar al Servei de Comunicacions d'aquesta universitat. En aquest sentit, al primer número de Papers, shi recullen alguns dels meus treballs - en aquest cas, el Seminari de Sociologia Rural- i aportacions d'en Cano.

Jo diria que Juli Busquets va ser sempre un bon company, un bon company en les reunions. Era una persona al egre, que sabia combinar la feina. Em prenc la llibertat d'explicar que moltes vegades havia de fer hores extraordinàries anant a visitar algú a no sé on, 0 anant a mirar no sé què més. I sempre hi anava amb les companyes $i$ els companys del $D$ epartament. És a dir, va ser una persona que sempre va tenir dues, tres coses entre mans, fins al punt que tots teníem por d'anar amb ell amb cotxe perquè conduïa sempre mig adormit en Ilocs tan perillosos com l'Arrabassada. I això passava a causa de la seva dedicació a moltíssimes coses.

Jo penso que el més important d'aquells dos cursos dels anys 1970-1971 i 1971-1972, fou haver treballat amb una persona de qui vaig aprendre, amb qui vaig sentir que érem uns bons companys, i al mateix temps que a mi em va, també, inculcar un esperit de servei al país. En aquell moment tots estàvem en grups polítics diferents aquell on ell «militava». En aquest sentit, el Juli 
Busquets i jo no coincidíem, però ho discutíem. Jo mén recordo que era una persona amb la qual es podia dialogar, parlar perfectament, i argumentar. Els estudiants d'aquella època no ho van comprendre així. Recordo que ell va patir moltes oposicions. O posicions, jo crec, totalment incompreses, perquè el Juli era una persona que s'hi jugava la vida de veritat. En canvi, al gunes de les persones que, en aquell moment, varen crear-li, fins i tot, algun problema a les classes, no entenien el que es feia realment al país en aquell moment. Per tant, Juli Busquets era al gú que estava sempre entre dues lluites: treballava per un ensenyament de qualitat, era una persona que estava al dia. I prova d'això és que ell va ser una de les persones que em va aconseguir un dels contactes quan jo vaig anar a estudiar a Anglaterra: una persona important com en C arr, perquè era un dels historiadors sobre Espanya més ben considerats en aquell moment a les principals universitats europees. És a dir, ell tenia bons contactes, coneixia revistes bones, i era una persona que en això t'ajudava moltíssim. Per tant, mantenia la lluita per aquest ensenyament de qualitat.

Al mateix temps, Iluitava, dins de la clandestinitat, a les files de la Unió M ilitar D emocràtica, i ho feia a cara descoberta pels plantejaments democràtics. Jo penso que cal haver viscut aquell moment per veure que això tenia molt de valor. Era una persona que va ser represaliada, perseguida, i que fins i tot després, en l'època democràtica, no se li van voler reconèixer al guns dels seus mèrits. I tot això va fer-ho, realment, de manera convincent i amb molta disciplina. En aquest sentit, també diria que fou un professor innovador. En el context de la D ivisió de Ciències Socials, Juli Busquets va assistir a tots els cursos de formació que s'hi impartien. Parlar d'anar a cursos d'informàtica l'any 1970, potser, actualment, a molta gent li semblarà ridícul, però realment, aixó vam fer-ho i en vàrem aprendre el que vam poder. Es va anar, també, a uns altres seminaris que es feien en altres universitats, és a dir, aquest desig d'aprendre d'una persona que anava sempre enfeinada, era molt important. Jo penso que era un bon exemple. Era com dir: «Fem la feina però no perdem la nostra obligació social». Vaig acceptar una beca del Patronat de la U AB, vaig marxar durant dos anys a Anglaterra i per aquest motiu vaig perdre la seva relació més directa. A la vegada, vaig entrar en contacte amb la geografia a través, també, dels membres de la D ivisió de Ciències Socials i em vaig anar decantant, agafant obligacions de seminaris més geogràfics. I llavors va succeir un fet que jo conec poc, que va tenir lloc entre l'any 1973 i el 1975: I'arribada d'un nou professor de Sociologia, el M arzal, i més endavant, el D e M iguel, i la idea d'anar creant un departament de sociologia, que també va significar anar creant un departament de geografia. En definitiva, això va anar provocant una selecció del professorat el resultat de la qual fou - encara que es tracta d'un procés que no conec gaire bé, i prefereixo no dir-ne més- la meva renúncia a seguir com a ajudant de Sociologia, el fet que el $C$ ano va haver de portar a terme al tres feines a la U niversitat, més endavant, i la demanda de Juli Busquets de continuar sent-hi físicament, tenint el despatx al D epartament de G eografia.

També diria que en Juli fou un professor de fons: una persona que va saber mantenir durant molts anys la seva activitat. A partir del 1982 va ser diputat 
a M adrid, és a dir una persona que tingué un nou tipus d'activitat, però no va voler deixar de fer classes. I crec que això, en un professor, és molt important. Ell venia a fer les seves classes de Sociologia a la Facultat de Lletres, i - al mateix temps- tenia classes molt nombroses, mantenia el contacte amb els seus alumnes, i va continuar fent $\mathrm{e}$ seu mestratge. El seu despatx va ser al corredor de G eografia fins l'any 1988. Allà hi tenia els seus arxius de la U M D i va estar entre nosaltres. N omés voldria acabar dient que durant aquests vint anys d'estar - d'una manera o una altra - a la Divisió de Ciències Socials, o al D epartament de Geografia, com deuen creure tots els companys i companyes (em sembla que puc parlar en nom de tots: els que estem al D epartament de G eografia o D idàctica de les Ciències Socials), en Juli fou un bon company, tant professionalment com a nivell de tracte personal, i també des del punt de vista de la lluita cívica i política que realitzàvem. Per acabar, voldria agrair el fet que se'ns hagi convidat a ser en aquesta mesa, i dir que cal conservar Juli Busquets - que ens ha deixat molt abans del que li corresponia- en la memòria com un gran professor d'aquesta casa i un company que ens ha sabut molt greu de perdre. 


\section{Joan Botella}

Els organitzadors d'aquest acte d'homenatge i de record a l'amic Juli Busquets m'han convidat a participar-hi en una doble condició. D'una banda, per la meva especialitat acadèmica, el sestudis polítics, i, en segon lloc, per les meves responsabilitats actuals com a degà del $\mathrm{Col} \cdot$ legi de Sociòlegs i Politòlegs de Catalunya. D eixeu-m'hi afegir que, a part del nostre contacte actual en aquesta facultat, també vaig poder ser alumne seu fa molts anys, a la Facultat de D ret de la U niversitat de Barcelona, etapa de la qual també us en puc esmentar al guna anècdota.

En tot cas, agraeixo molt sincerament als organitzadors d'aquest acte la seva invitació, que em permet afegir-me a l'homenatge a una persona de la rellevància i de les qualitats humanes d'en Juli Busquets. El Busquets polític té dues etapes de clara projecció i significació general, encara que ben diferents entre elles. $\mathrm{H}$ avia ingressat de molt jove a l'A cadèmia General M ilitar, procedent, en termes polítics i ideològics, segons propia confessió, de l'extrema dreta. Però progressivament aquests origens aniran quedant enrere. Ja militar, oficial del cos d'enginyers, es trasllada a M adrid per realitzar-hi el curs d'Estat M ajor, i simultaneja aquesta dedicació amb els estudis de Polítiques a la vella Facultat de $M$ adrid, on comença a preparar la investigació que conduirà més tard, a la seva tesi doctoral sobre El militar de carrera en España.

I és en aquella época, a la Facultat, on entra en contacte amb persones, amb llibres i amb maneres de viure molt diferents, on comença un camí que el portarà molt lluny. Per esmentar-ne només una referència poc coneguda, la segona edició de la tesi és segrestada, i ell mateix serà processat pel llibre (tot i que la causa serà arxivada anys més tard). Avui fer una tesi doctoral pot ser considerat com un requisit acadèmic, o com la producció d'un bon treball d'investigació, però a l'Espanya de fa trenta anys podia ser un risc polític i judicial ben concret.

D estinat a Barcelona, entra en contacte amb el D epartament de D ret Polític de la U niversitat de Barcelona, on en aquell moment hi ha noms clau de la política antifranquista, com ara M anuel Jiménez de Parga, Jordi Solé Tura, Isidre M olas, o encara d'altres. I molt possiblement en aquests contactes s'accentuen els elements de ruptura política i ideològica amb el règim franquista. El 1970 promou una carta col-lectiva al príncep Joan C arles i al tinent general D íez Alegría, en què demana l'obertura del règim. Firmada per un reduït grup d'oficials, aquesta carta assenyala l'inici d'una sensibilitat nova dins l'Exèrcit.

No cal equivocar-se respecte d'aquesta sensibilitat. No es tracta d'un plantejament radical, ni de ruptura, ni de bon tros de considerar cap mena d'acció política per part de militars. El que s'afirma és la necessitat de desenganxar la institució militar d'un règim polític dictatorial, que en aquell moment està entrant en la recta final. (Per a qui vulgui saber més, sobre aquest aspecte i sobre molts altres de la seva vida, aconsello molt sincerament el seu llibre de memòries, publicat fa un parell d'anys, M ilitares y demócratas.) 
El règim reacciona amb virulència i, en el seu cas, comencen els arrestos. D eixeu-me esmentar un record personal: en el curs 1969-1970, en Busquets va impartir un seminari a la Facultat de D ret, sota el títol de «Sociologia Política», al qual ens vàrem inscriure tots els estudiants que, tot i no saber res de qui era en Busquets, teníem curiositat i interès per les qüestions polítiques. D e fet, el seminari no va ser fàcil, ja que entre aquells estudiants els més moderats devien ser maoistes. Però quan en Busquets hi va faltar dues setmanes seguides i vàrem anar a preguntar què passava, va ser quan vàrem descobrir tant la seva condició militar com la seva situació d'arrestat per defensar valors i idees contràries al règim franquista.

Aquesta sensibilitat es va difondre, encara que en dosis mínimes, en el si de les forces armades. Q uan, I'any 1974, en Busquets, juntament amb altres militars demòcrates, com ara $\mathrm{O}$ tero, Reinlein, Cardona i d'altres creen clandestinament la U nión de M ilitares D emócratas, I'objectiu no és enderrocar el règim, sinó fixar un plantejament polític dins l'Exèrcit, que pogués neutralitzar les temptacions militaristes dels sectors més reaccionaris del franquisme. Poc a veure, per tant, amb la revolució dels clavells a Portugal del mateix any, on van ser uns oficials de grau mitjà els que varen encapçalar l'alçament popular que va enderrocar la dictadura.

Però el precedent portuguès va pesar molt dins l'Exèrcit espanyol. Per una banda, la U M D va concitar l'odi ferotge del búnquer franquista, que els considerava, pel cap baix, traïdors; de fet, Busquets va passar sis mesos a la presó l'any 1975. Però, a la vegada, el precedent portugues i la pròpia existència de la UM D (de la qual ningú sabia quin abast i dimensions tenia) van efectivament contribuir a bloquejar els intents de fer jugar de manera activa la força conservadora de l'Exèrcit per impedir el canvi democràtic.

Aquí Busquets arribava al final d'una etapa. S'havia transformat, en les seves pròpies paraules, «en algo tan pintoresco como un militar demócrata y catalán». I aquí va decidir fer el gran pas: s'adhereix al Partit Socialista, es dóna de baixa com a militar i es presenta com a candidat al Congrés a les eleccions del 1977, i va ser elegit contínuament fins a la seva sortida de les cambres, l'any 1993.

Al Ilarg dels setze anys de la seva activitat parlamentària, Busquets s'especialitza en temes militars i de defensa, participa activament en el debat sobre la Constitució i després sobre l'E statut, i adopta un paper enèrgic en la reivindicació de la memòria dels militars de la U M D. Aquests havien estat expulsats de l'Exèrcit com a represàlia per la seva activitat, i Busquets (i molts al tres) creien que, com tots els altres delictes polítics comesos durant el franquisme, I'activitat de la U M D havia de ser valorada i els seus homes, amnistiats. Però la pressió dels poders més directament fills del franquisme va aconseguir que la llei d'amnistia del 1977 no inclogués els homes de la U M D. M algrat moltes pressions, i per una sola vegada, Busquets es va sentir obligat a trencar la disciplina de partit i a votar contra la llei.

Al costat del Busquets militar i polític, em toca també parlar-vos d'un altre Busquets. No exactament del sociòleg, investigador i acadèmic, sinó del pro- 
fessional, molt conegut dins del gremi dins i fora d'Espanya. D e fet, va ser un dels primers que va utilitzar l'etiqueta de sociòleg a Espanya, al costat d'altres il-lustres noms del que es pot considerar la primera generació de sociòlegs acadèmics estàndard (des de Salustiano del Campo fins a Amando de M iguel, passant per D íez N icolás o d'altres). Això li va permetre desenvolupar un paper actiu en la consolidació de la professió, de tal manera que quan es va crear el I'Ilustre Colegio N acional de Licenciados y D octores en Ciencias Políticas y Sociología, ell en va ser el col·legiat número u (i ja sabeu com en són de sensibles els militars a la cosa de l'escal afó!). Per tant, era natural que quan es va crear el col·legi català l'any 1990, en Busquets s'hi incorporés i, novament, ho fes com a membre número u de la nova institució.

En Busquets sho prenia seriosament. Ell estava convençut que la universitat, i els professors individualment, adquireixen responsabilitats respecte dels estudiants, no només mentre estudien, sinó també després. I aquesta responsabilitat s'havia de materialitzar en un paper actiu de promoció del'ofici i de suport als joves professionals. Per això serveixen els col·legis professionals, i per això en Busquets hi participava d'una manera notable.

Ja us dic que s'ho prenia seriosament. Encara pocs dies abans del final, en Busquets era aquí, corregint exàmens i entrant notes a les actes. Fins i tot el dia abans, tot i que s'havia anat allunyant dels punts de vista majoritaris en el seu partit, encara va assistir a una reunió on li varen entregar un distintiu commemoratiu. Aquesta tenacitat, aquesta virtut resistent, aquest «no amagar-se» davant res, són les lliçons més profundes i més entranyables que n'hem pogut treure.

M oltes gràcies. 


\section{M aria Pia Barenys}

Voldria agrair, en primer Iloc, al president d'aquest acte, el professor Fausto M iguélez, degá de la Facultat de Ciències Polítiques i Sociologia que m'hagi convidat a compartir la mesa i pugui realitzar la meva intervenció amb més comoditat. Aquesta intervenció tindrá dues vessans. U na, com a portaveu de la família, que així m'ho ha encarregat, i l'altra, com a companya del D epartament de Sociologia del professor Juli Busquets des de l'any 1974, en el qual vaig iniciar la meva tasca docent en aquesta universitat.

Com a familiar, vull agrair al D epartament de Sociologia i a la Facultat de Polítiques i Sociologia l'organització d'aquest acte. I agrair especialment a les persones que fan tasques de secretaria en l'una i l'altra, en especial a l'Ángela Palau, a la Isabel Rodríguez, al D aniel Pérez i a la N úria Solé. També a totes aquelles persones que han intervingut d'una manera 0 altra en aquest acte per dur a terme I'homenatge. I, tanmateix, agrair a la Biblioteca de Ciències Socials a la seva cap M otserrat Catafal i a la M ontserrat Rabat i al Raül Coré l'organització d'una acurada exposició de l'obra i dels principals trets de la vida d'en Juli Busquets, que es va inaugurar fa uns quants dies i que romandrà oberta encara durant un mes. Així mateix, aprofito aquest acte per comunicar que part del llegat de la biblioteca personal d'aquest professor ha estat donada a la Universitat Autònoma.

Voldria manifestar-vos que, per als familiars, aquest és un acte íntim. Íntim en el sentit que, avui, encara que ells haguessin estat a la U niversitat Autònoma per altres motius - un dels fills, hi va cursar la llicenciatura de M edicina i la seva filla va col·laborar a recollir el despatx del Juli per tal que al setembre, a l'inici de les classes, com ell hagués volgut, fos a disposició del $D$ epartament- 0 bé haguessin pujat a l'Autònoma en altres ocasions, avui han fet un recorregut de comiat per aquells llocs que havien emmarcat la vida docent del professor Busquets. $\mathrm{H}$ an estat rebuts cordialment pels companys que avui representen les institucinons organitzadores d'aquest acte i també han visitat l'exposició organitzada per la biblioteca, de la qual abans he fet esment.

Però també vull fer referència, una vegada més, a la intimitat d'aquest acte. Penseu que la vida dels familiars més próxims d'en Juli ha estat impregnada, durant molts anys i fins al final, de la seva actvitat docent. Per posar-ne un exemple, molt sovint el telèfon sonava i els seus fills, encara petits, o la meva germana M ontse, atenien les trucades de companys de la U AB. Encara avui, saben de memòria noms i cognoms que formen ja part de la seva infantesa i que han format part de la seva vida quotidiana. I avui n'han pogut saludar uns i conèixer-ne uns altres personal ment.

Una mostra de com en Juli Busquets vivia aquesta companyonia és que sempre estava disposat a ajudar, o a donar consell a qui se'l volgués escoltar. $M$ olts dels companys (ara intervinc en la meva vessant acadèmica) que som aquí, en aquest acte, sobretot els més antics, li vàrem poder retornar aquesta solidaritat en un moment clau de la seva vida. En efecte, l'any 1975 el M oviment de PN N (professors no numersris) estava en ple auge. L'Assemblea de PN N 
de la U AB contemplava sempre, en el seu ordre del dia, un punt d'informació, que, normalment, cobria jo en la meva doble vessant, sobre la situació del processament i l'empresonament del professor Juli Busquets. Recordo com l'Assemblea seguia amb molt interès totes les notícies que n'arrivaben i especialment aquelles obtingudes de primera mà quan la meva germana i dona d'en Juli i els seus fills, que al eshores eren molt petits, havien anat a visitar-lo a la presó militar d'El H acho (Ceuta).

Aquesta solidaritat encaixava perfectament en la politització del paísi, evidentment també, amb el M oviment de PN N de les universitats. A I'Autònoma hi havia una consciència clara dels riscos a què s'havia exposat el professor i capità de l'exèrcit Juli Busquets i que el seu processament i posterior empresonament es devia principalment a la publicació de la seva tesi doctoral i a la seva actitut docent i generosa en tots els àmbits de la seva vida.

Aquesta part de la història ha quedat documentada en les dues cartes que li vàrem enviar els seus companys dels respectius departaments de G eografia i Sociologia, on ell impartia docència, en les quals li manifestàvem que el trobà vem a faltar i que desitjàvem que aviat estigués de nou entre nosaltres. Aquestes dues cartes, que es poden veure a l'exposició, en Juli Busquets les va conservar emmarcades en el seu despatx de la UAB. Ahir, quan l'Enric Lluch em comunicava que la seva salut li impedia ser present en aquest acte, em va dir que estava buscant una carta que ell, com a director del D epartament de G eografia, havia enviat al tinent coronel d'El H acho perquè el deixés sortir a examinar-se. Petició que va resultar rebutxada, i que tenia com a principal objectiu alliberarlo per uns quants dies del seu empresonament.

Un altre aspecte que és conseqüència de la seva generositat, i que voldria ressaltar, és l'actitud de companyonia tan habitual en ell, i de la qual, jo crec, en va fer una manera de relacionar-se amb la gent. Per posar-ne exemples: era una persona accessible, que es prestava que li consultessin sobre qual sevol tema, tant pels estudiants com pels professors. Si ell creia, amb la humilitat de tot científic i que era també una actitud remarcable seva que el caracteritzava prou bé, que d'aquell tema no en podia en donar una resposta prou completa, sempre orientava el seu interlocutor perquè pogués resoldre o encaminar les seves inquietuds. Al mateix temps no dubtava a preguntar a d'altres persones per tal de completar els seus amplis coneixements.

Aquesta actitud de companyonia el va portar a animar i a ajudar els professors més joves. Una professora, que avui dia és titular, em comentava que quan ella va començar a impartir classes, el professor Juli Busquets li havia deixat els seus propis apunts manuscrits per preparar al guns temes, i m'ho explicava amb tota l'admiració i agraïment possible que els seus ulls podien expressar. Ú nicament, crec, els que som docents podem apreciar la magnitud d'aquesta acció amb tota la seva amplitud. A alguns professors ens va donar l'oportunitat de fer amb ell un simulacre d'exercici d'oposició o de lectura de tesi que ell presenciava pacientment amb l'esperit crític que també el caracteritzava.

$D$ 'aquest esperit crític i dels seus principis ètics m'agradaria parlar-ne també breument. En Juli Busquets era una persona que deia el que pensava i en el 
moment i en l'àmbit que creia que ho havia de dir, encara que això li comportés enemistats o no agradar a tothom. Aquets dos aspectes de la seva personalitat i, per tant, de la seva manera de ser, es varen posar en relleu en les seves intervencions en les juntes i consells de facultat i de departament respectivament, instàncies en les quals, quan ell creia que calia, recordava al collectiu allí reunit que, per sobre de tot, la universitat era un servei públic. Al mateix temps, el seu entrenament en la política feia sovint que les seves intervencions intentessin consensuar posicions en principi distanciades, a les quals oferia una tercera via de sortida. Aquesta barreja de l'esperit crític, de l'ètica i de la política, en resum, de la vida compromesa entesa com a servei a favor de la justícia i l'equitat per esborrar tant com fos possible les desigualtats socials, diria que varen constituir el pal de paller que va marcar la trajectòria vital d'en Juli Busquets.

Aquests principis li varen fer prendre la decisió de continuar el curs fins al final, encara que les molèsties de la malaltia, que anaven en augment, fessin cada cop més feixuga la seva decisió, de la qual no es va fer mai enrere. El principal era no abandonar la tasca docent a la qual s'havia compromès i que li agradava per sobre de qualsevol altra. Com varen difondre els mitjans de comunicació, va corregir els exàmens de la convocatòria de juliol fins pocs dies abans de morir.

La seva actitud ètica li va servir per acceptar amb dignitat i coratge la seva mort anunciada un any abans. D urant aquest temps va anar preparant-se i preparant la seva desaparició intentant preveure el més minim detall, principalment pel que fa referència a la seva obra, per tal que els que la volguessin continuar ho poguessin fer amb tot tipus de facilitats. La dignitat i el coratge amb què s'enfrontava a la seva mort em va fer pensar, per tot el que, a la mort, temps ençà, ja li havia plantat cara.

Q uan vaig tornar al setembre - en Juli Busquets havia mort el 21 de juliol del 2001- , companys i personal no docent em varen donar el condol per la pèrdua del professor $i$, al mateix temps, m'expressaven a mi i a la direcció del D epartament, és a dir a l'Andreu Lope, la necessitat de retre-li un acte d'homenatge. $D$ 'entre totes aquestes mostres d'afecte cap a la seva persona, faré únicament menció a la conversa que vaig mantenir amb M aría Guillén. La M aría Guillén realitza tasques en horari de tarda al despatx de bidelleria i li vaig fer saber que en Juli, a més de company de departament, era també familiar meu. Em va dir que sentia molt la mort d'aquest professor, que per a ella era una bona persona, agradable i educada i que sabia agrair, amb la seva actitud respestuosa, les atencions que en els últims temps el personal d'aquest despatx tenien amb ell. També em va dir que suposava queli farien un acte i que ella hi voldria assistir, i avui, com tants d'altres companys, s'ho ha arreglat per poder, fora del seu horari de treball a la UAB, estar amb nosaltres. Gràcies a tots.

Respecte als seus companys, en Juli em va deixar l'encàrrec que, abans de desfer el seu despatx, ells hi entressin i n'agafessin els llibres que els poguessin interessar. C om em deia una companya de departament l'altre dia, aquest acte 
homenatge, que ha consistit a recórrer la vida i, lògicament, l'obra del Juli Busquets, és un acte que també l'hem fet per a nosaltres, perquè necessitem acompanyar-nos en la pèrdua del nostre company.

Finalment, vull parlar del Ilegat que crec que ens ha deixat als seus companys i a les institucions acadèmiques aquí representades: continuar l'intercanvi d'aquesta Universitat amb la U niversitat de l'H avana. D e tots són coneguts els esforços que va dedicar a aquesta causa, fins al final, i de la qual han resultat cursos, seminaris, diplomatures, que han donat Iloc a diverses publicacions, iniciatives a les quals companys del D epartament de Sociologia i d'altres departaments, amb ell com a capdavanter, ens hi hem anant sumant. Aquesta riquesa, aquest teixit de relacions socials, ja endegat, no el podem abandonar. Seria, per la nostra banda, engegar a rodar l'última part de la seva memòria.

Crec que podem recordar en Juli com, el que endevino, va voler ser, un company generós. Potser ens caldria preguntar-nos si vàrem saber estar sempre a la seva al çada. 